\title{
JOVEM APRENDIZ COMO UMA NOVA PERSPECTIVA DE INCLUSÃO SOCIAL
}

\author{
Alan Dyohnathan da Silva Gomes ${ }^{1}$ \\ Michele Aline Nascimento Souza ${ }^{2}$ \\ Eduardo Otávio Ferreira Vasconcelos ${ }^{3}$ \\ Gilson Scholl Pires ${ }^{4}$
}

Resumo: O jovem, pela sua inexperiência, tem encontrado pouca ou nenhuma oportunidade diante de tantas exigências. Dessa maneira, o estudo pretendeu analisar as contribuições do Programa Jovem Aprendiz na vida pessoal e profissional dos jovens belenenses. A pesquisa foi realizada na cidade de Belém (Pará), envolvendo estudantes que participaram do projeto. O método utilizado foi de caráter exploratório e quantitativo. Assim, mediante as dificuldades e particularidades que os jovens enfrentam na busca do primeiro emprego, ficou evidente que o referido projeto contribui para transformação pessoal e social dos jovens em fase de desenvolvimento. Concluiu-se que a inserção do jovem no mundo do trabalho, pelo programa, os prepara com habilidades e competências que contribuem para a formação teórico-prática, modificando suas vidas no ingresso no ambiente profissional de maneira satisfatória.

Palavras-chave: Programa de Aprendizagem; Aprendiz; Inclusão Social.

\footnotetext{
${ }^{1}$ Bacharelado em Administração/Faculdade Metropolitana da Amazônia, Brasil. E-mail: adm.alan@ymail.com. 2 Bacharelado em Administração/Faculdade Metropolitana da Amazônia, Brasil. E-mail: micheleansouza@yahoo.com.br.

3 Mestre em Gestão e Desenvolvimento Regional pela Universidade de Taubaté - UNITAU; Professor da Faculdade Metropolitana da Amazônia, Brasil. E-mail: vasconcelos_edu@yahoo.com.br.

${ }^{4}$ Mestre em Administração pela Universidade da Amazônia - UNAMA; Professor da Faculdade Metropolitana da Amazônia, Brasil. E-mail: gilson.scholl@gmail.com.
} 